\title{
Jacques Dubochet met ses convictions sur le papier
}

\author{
Jean Martin \\ Dr méd., membre de la rédaction
}

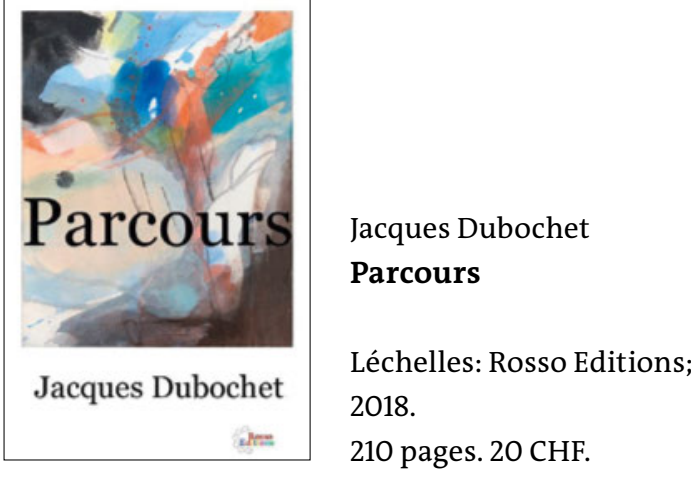

Guère besoin de rappeler la surprise, avec une dimension d'humour, qu'a été l'irruption le 4 octobre 2017, sur la scène sociétale et médiatique, du biophysicien J. Dubochet, auquel le Prix Nobel était attribué. Six mois plus tard, il publie un livre, présentation "globale» de ce qu'il est.

Trois parties: «Faire sens» réunit cinq textes de fond où il discute ce qu'il entendait dire en octobre, parlant en impromptu, sur ses engagements personnels et sociaux, y compris politiques. Il y parle de «bien faire», de science et philosophie. La seconde, «Tranches de vie», est constituée des briques peut-on dire qui ont construit sa carrière. Dans un texte, "Vivre et mourir», il donne même ses directives anticipées. La troisième, «De la science en miettes», comprend des notes rédigées assidûment à l'intention de collègues et amis, un blog, sur ses lectures de revues scientifiques. Par exemple sur le dérèglement climatique - sur la technique CRISPR/Cas9 et le forçage génétique.

"'ai écrit le présent texte parce que je rencontre tant de gens qui n'ont pas compris que 'bien faire' n'est pas faire n'importe quoi et que 'bien vivre' se construit sur quelques fondements incontournables. Un bon point de départ est 'Fais à ton prochain ce que tu voudrais qu'il te fasse'.»

Conscience, évolution. «La conscience est à mon sens la capacité d'un individu à se construire un modèle mental du monde dans lequel il peut naviguer [...] Elle est aujourd'hui en rupture avec près de 4 milliards d'années de vie sur Terre. Jusqu'ici, l'évolution s'est déroulée selon le couple variation au hasard / sélection naturelle. Arrivent l'homme et ses capacités. L'évolution biologique est écrasée par l'évolution culturelle. La première se déroulait par millions d'années, les transformations culturelles se font maintenant par périodes de 10 ans. La mondialisation s'est installée et nous nous fourvoyons dans un changement climatique et l'ère anthropocène.»

Le Moi et le Nous. «L'homme repose sur deux jambes: le Moi et le Nous. L'une est typique de la réponse immédiate, l'autre appelle les solutions à long terme [...] A priori, égoïsme et altruisme se rapportent à des stratégies adaptées à différentes situations. Pourtant, dans le langage courant, ces mots ont une forte connotation morale [...] Pour moi, une personne est de gauche si elle tend à favoriser les valeurs altruistes; elle est de droite si elle met son intérêt propre en priorité.»

«Les bases de nos sociétés se transforment et souvent chancellent. Avec des défis vitaux. Laisser aller conduira à des catastrophes extraordinaires. Pour nous sauver, les solutions seront collectives ou ne seront pas. Notre société a un urgent besoin de consolider la force du Nous.» Dubochet parle d'éthique. «Bien faire se ramène à deux stratégies possibles: l'une est darwinienne [sélection naturelle], elle va de soi, elle poursuit aujourd'hui son écrasante efficacité. Comme la pierre qui roule vers la vallée, elle ne demande ni plan ni choix. La seconde stratégie prend de la distance. Elle se fait une image du monde dans laquelle l'Homme se voit, lui, parmi les autres.»

Retraite. Il est à la retraite depuis dix ans. «La difficulté est que chaque jour n'a que 24 heures. Le succès d'une journée de retraité dépend de la sévérité du tri. J'essaie d'équilibrer mes quatre S, à savoir: Soi-même, Social, Science et Service.»

«Le 27 septembre 2017, j'annonçais que je cessais la rédaction de mon blog pour me lancer dans un bouquin plus synthétique, du genre réflexions d'un vieil intellectuel. Une semaine plus tard, le 4 octobre, le Prix Nobel! L'urgence et la nécessité ont produit l'objet que vous avez dans les mains.» Il ne se laisse toutefois pas emporter: «Le Prix Nobel me donne une voix, celle de la notoriété. Je n’ai pas de respect pour la notoriété. J’ai du respect pour ceux qui essaient de vivre juste.» Parcours, une sorte de mosaïque/kaléidoscope stimulant pour approcher de plus près - avec profit! - ce scientifique atypique.* 